\title{
Call for nominations - CAG research and education awards, and members for CAG committees
}

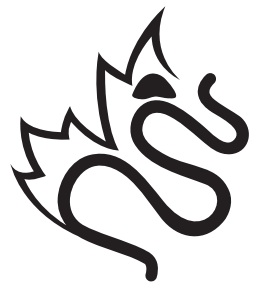

Canadian Association of Gastroenterology

En français voir page 642

\section{CALL FOR NOMINATIONS - CAG RESEARCH AND EDUCATION AWARDS}

Members of the Canadian Association of Gastroenterology (CAG) are invited to nominate individuals for the 2009 CAG research and education awards. All nominees must be members of the CAG. Descriptions of the awards, eligibility criteria and the process for nominating candidates are described below:

\section{Research awards}

CAG Visiting Research Professorship - offered annually (although not necessarily awarded) to a proven teacher and an outstanding researcher. The Visiting Professor visits several centres across Canada to present at gastroenterology or grand rounds, and/or research seminars.

CAG Research Excellence Award - each year, the Research Committee selects an outstanding Canadian Researcher to present the annual Research Lecture at Canadian Digestive Diseases Week (CDDW).

CAG Young Investigator Award - recognizes outstanding contributions to gastroenterology through basic and/or clinical research by a young investigator, who is invited to give a lecture at CDDW. Candidates must:

- be younger than 45 years of age and/or within seven years of their first academic appointment;

- hold an appointment at a Canadian university, hospital or research institute; and

- be a Canadian citizen or a landed immigrant resident in Canada.

Education awards

CAG Education Excellence Award - offered annually for outstanding contributions to education on a national or international basis. The contribution may be in the areas of teaching, research in education or development of educational programs. The recipient is invited to give a lecture at CDDW.
CAG Young Educator Award - recognizes outstanding contributions to gastroenterology through education by a young investigator, who is invited to give a lecture at CDDW. Candidates must:

- be younger than 45 years of age and/or within seven years of their first academic appointment;

- hold an appointment at a Canadian university, hospital or research institute; and

- be a Canadian citizen or a landed immigrant resident in Canada.

\section{Nominations process}

Nominations for the above awards can be made by any member of the CAG by completing and submitting on-line the fillable PDF nomination form found on the CAG Web site (under 'Research, CAG Research Awards' or 'Physician Education, Awards') at <http://www.cag-acg.org/uploads/ cagyinominationformweb.pdf $>$, or by sending the completed form by fax or e-mail to the CAG National Office:

CAG National Office

2902 South Sheridan Way, Suite 201

Oakville, Ontario L6J 7L6

Fax 905-829-0242

E-mail cagoffice@cag-acg.org

For all nominations, a copy of the candidate's curriculum vitae and a letter of support should be forwarded along with the nomination.

The Research and Education Committees will review the nominations and make recommendations to the executive, who will make the final decision regarding recipients. Selection will be based on the research or education record of candidates.

The deadline for receipt of nominations is July 31, 2008.
Abbott Canada
Olympus Canada Inc
AstraZeneca Canada Inc
Pentax Canada Inc
Axcan Pharma Inc
Nycomed Canada Inc
Procter \& Gamble Pharmaceuticals
Schering Canada Inc

The CAG is proud to acknowledge its Benefactor Corporate Sponsors: 


\section{CALL FOR NOMINATIONS - MEMBERS FOR CAG COMMITTEES}

CAG members are encouraged to become involved in the organization to help promote its development and gastroenterology in Canada. The Nominations Committee is looking for members with an interest in serving on a CAG committee. Terms are three years, with committees 'meeting' through periodic teleconferences. The frequency of these teleconferences is determined by the activity of the particular committee. Committees for which representatives are needed for the 2009 to 2012 term are listed below, along with a short description of the mandate of the committees.

\section{CAG committees}

Archives: Maintain the records and history of the CAG.

Education: Promote/disseminate educational material/training for the CAG and provide direction to the various education subcommittees.

Endoscopy: Represent CAG on matters relating to endoscopists, and promote competence and training in endoscopy. Finance: Together with the national office and executive, strategize and implement fundraising for corporate sponsorship and key initiatives such as CDDW and research.

Pediatrics: Represent the interests of pediatric gastroenterologists to the CAG board and membership.

Practice affairs: Address issues relevant to practising gastroenterologists. Representation from Alberta, Ontario and Atlantic Canada are needed for 2009 to 2012.
Research: Promote basic and clinical research by:

- reviewing and selecting candidates for research funding;

- reviewing and deciding on acceptance of CDDW abstracts and student prizes; and

- helping to develop the program for CDDW.

If you are interested in serving on a CAG committee or know a member who would be, you are encouraged to submit nominations for positions to the CAG National Office by mail, fax or e-mail:

CAG National Office

2902 South Sheridan Way, Suite 201

Oakville, Ontario L6J 7L6

Fax 905-829-0242

E-mail cagoffice@cag-acg.org

All nominations will be reviewed and considered by the Nominations Committee, which will recommend candidates to the Governing Board for approval. Candidates approved by the Governing Board will be circulated to the Membership and will be given final approval at the Annual General Meeting.

Submission of nominations on or before August 31, 2008 would be appreciated. 


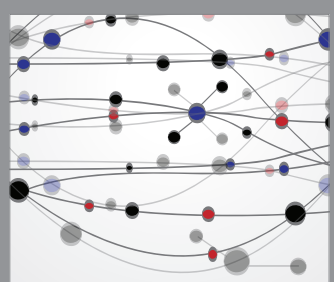

The Scientific World Journal
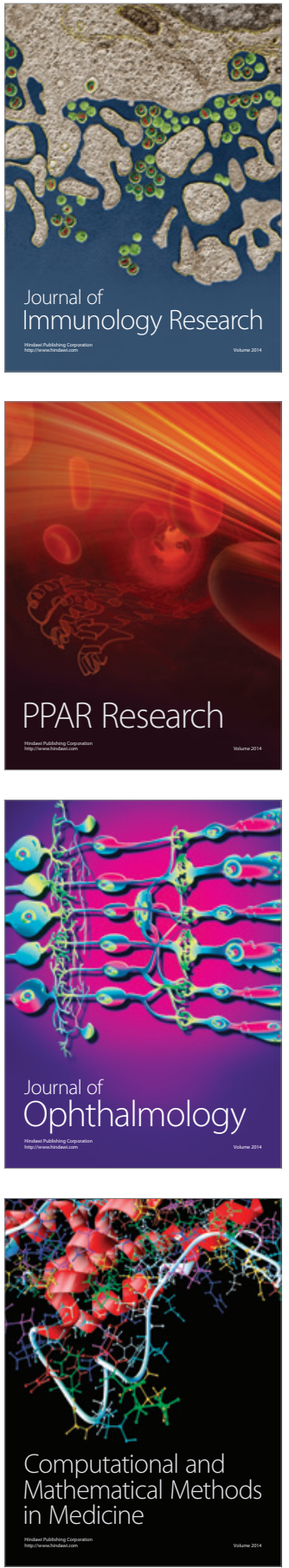

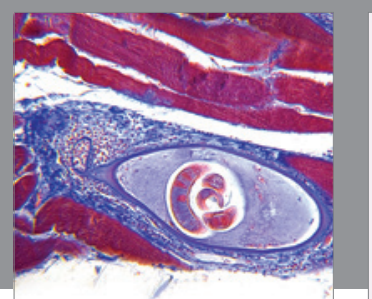

Gastroenterology Research and Practice

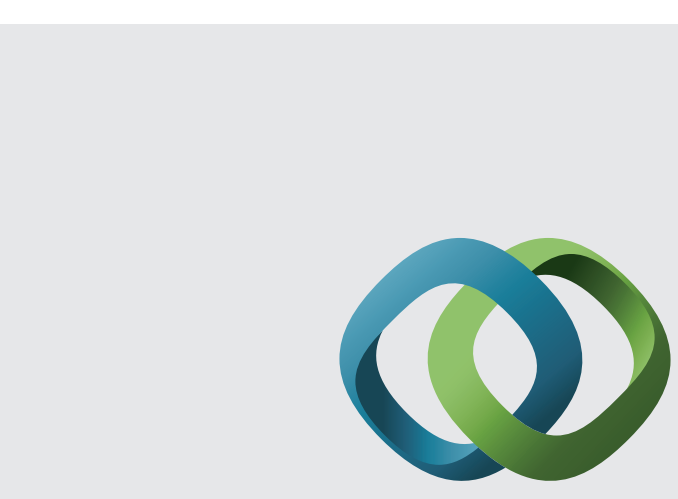

\section{Hindawi}

Submit your manuscripts at

http://www.hindawi.com
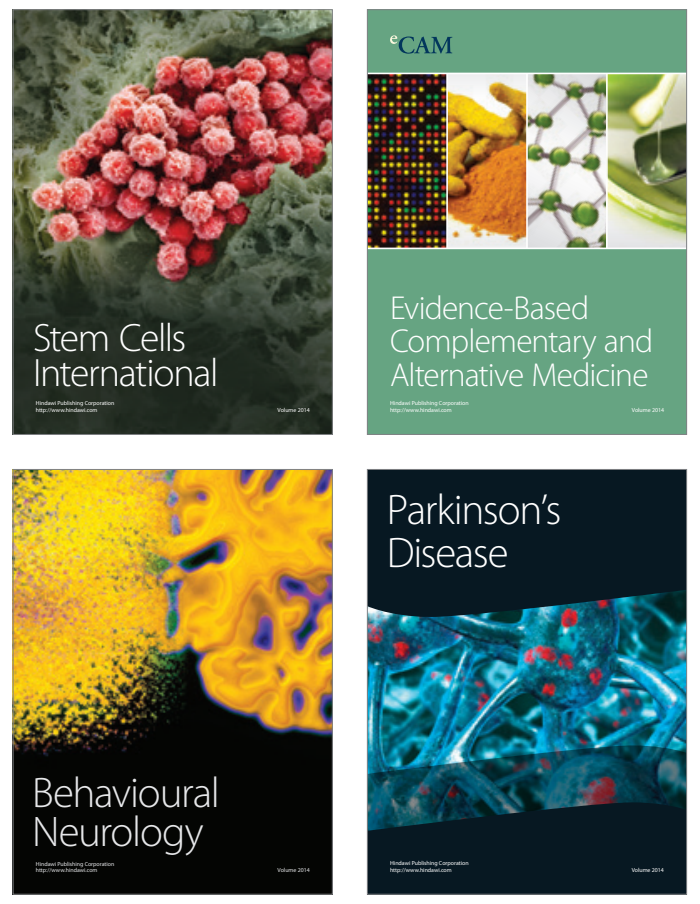
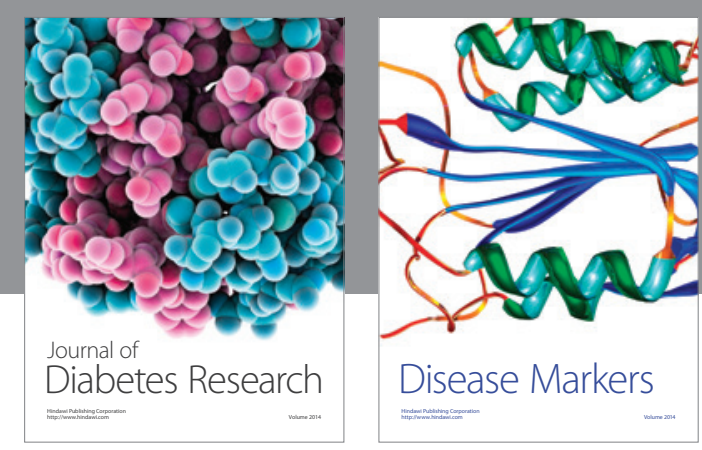

Disease Markers
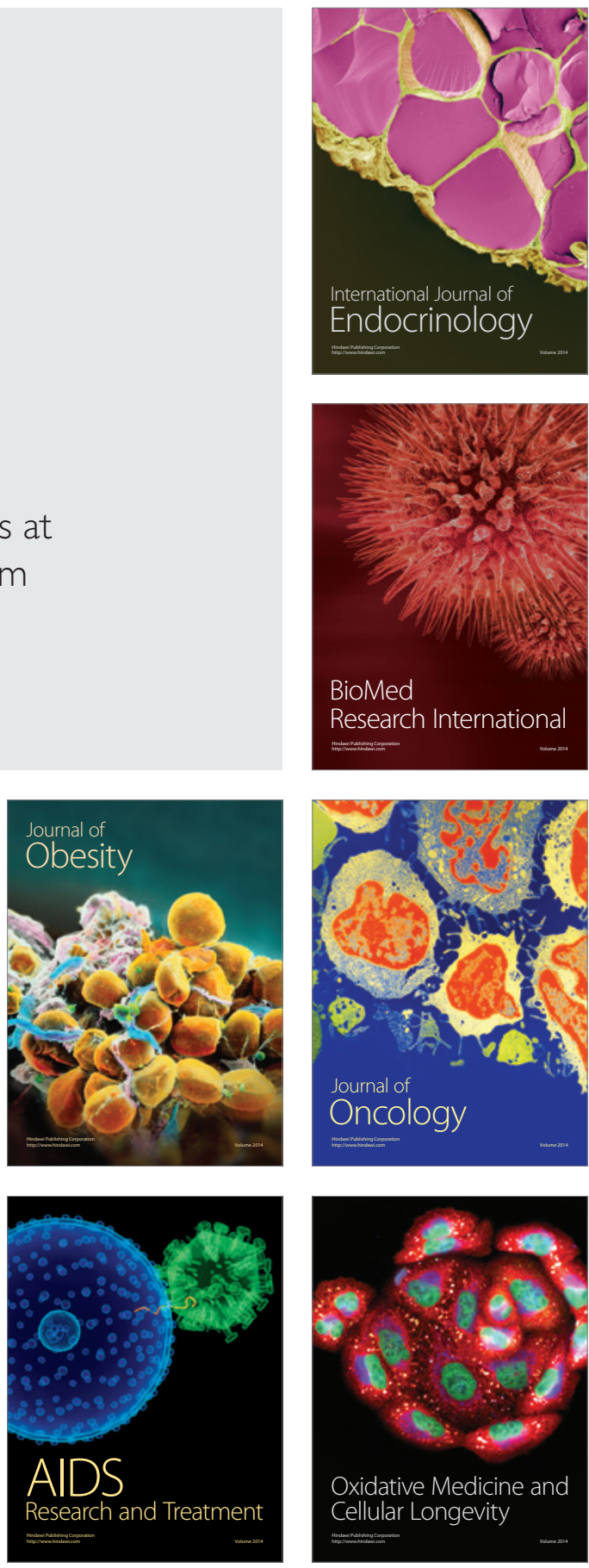